\title{
Device of Remote Centralized Monitoring for Streetlights of Intelligent
}

\section{Community}

\author{
Fang Zhao ${ }^{1, a^{*}}$, Yongmei Su ${ }^{1, b}$ and Xiaomei Zheng ${ }^{1, c}$ \\ ${ }^{1}$ Zhengzhou Technical College, Zhengzhou 450121,China \\ aemail:zhaojifang216@126.com, bemail:491758574@qq.com, cemail: zztixiaomei@126.com
}

Keywords: Community Streetlights; MSP430 MCU; Energy-Saving; Remote Monitoring

\begin{abstract}
Intelligent community's streetlight can't achieve remote monitoring, based on this problem, the remote monitoring system is designed for intelligent community of streetlights, the MSP430 micro-controller is as the core controller, the detection circuit can automatically determine that streetlights is good or bad and the fault location, PC monitoring software is developed, the fault details are sent to the monitoring center and the attendant phone by GSM wireless network. Only one person can control and manage all lights' fault conditions, the design achieve all lights' centralized group control, at the same time, the design saves management cost. This design makes a test prototype, the test prototype achieves the desired operational results. The design can also be applied to the centralized monitoring and management of urban street lamps.
\end{abstract}

\section{Introduction}

With the rapid development of Chinese cities, economic society and the continuous improvement of people's living standards, people have put forward higher requirements for the safety, comfort, convenience and information of living environment. Intelligent residential area in China's booming, intelligent community road lighting and lighting landscaping project is an indispensable content of each district. At present, the management of intelligent residential street lamp is mainly by manual inspection, with the increase in the number of residential street, the property takes a lot of manpower and material resources to conduct inspection and maintenance, this mode is easy to form a corner by artificial inspection, easy to create opportunities for criminals to commit crimes. At the same time the cost of living is increased. Therefore, the good and bad automatic detection and remote centralized monitoring have become an important aspect of intelligent management of residential area. Based on this, the centralized remote monitoring device of street lamp based on GSM is designed.

\section{The Whole Design of System}

At present, the working condition of the intelligent residential street lamp mainly adopts the time control mode to open and close, street lamp's bad or good is mainly rely on manual inspection. The design of intelligent residential all street lights' good or bad is put forward with automatic detection 、 centralized monitoring and automatic fault alarm. SCM is responsible for collecting information on each street, the fault information each street lamp collected by SCM will be sent to the Monitoring Center PC and the operator's mobile phone through the GSM network [1]. This design can realize the centralized monitoring of all the street lamps and landscape lamps. The duty officer can control the working status of each street lamp in time and conveniently. If the street lamp is damaged, the 
system will send the alarm information its' location information of the street lamp to the monitoring center in time, so that it can be repaired in time. The software of the upper computer monitoring center is provided with a database, which can provide historical data query, statistics and other functions. The remote monitoring function of the system provides convenience for the property management personnel, and saves a lot of manpower, greatly reducing the cost of property management. The overall structure of the system is shown in Fig. 1:

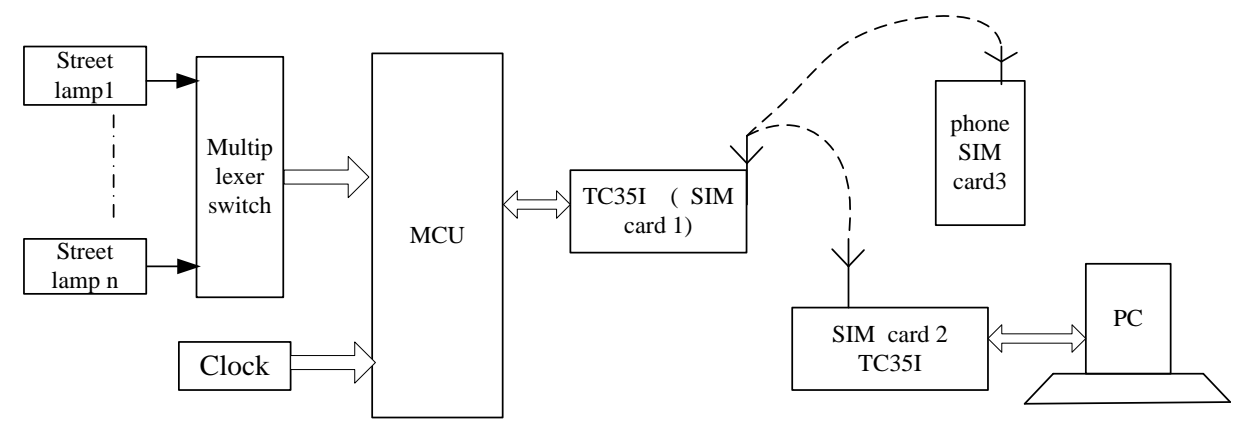

Fig. 1 The system structure block diagram

\section{Hardware Design}

\subsection{Controller Selection}

This design chose the American TI company's high efficiency 16 bit RISC-CPU microprocessor MSP430F149 with ultra low power as the core controller of this system [2]. The controller has low power consumption, low voltage power supply, wide voltage range: $1.8 \sim 3.6 \mathrm{~V}$, strong interrupt function, ESD protection, strong anti-interference ability, wide operating environment temperature range, suitable for industrial environment [3]. The controller with 12 bit A/D converter and 2 serial communication interface module can meet the needs of the design. When the street lamp is working, the single chip computer is in the state of low power consumption mode, when a fault occurs or the host computer sends out the instruction of the street lamp, the single chip microcomputer is automatically awakened, and the control device can achieve the goal of saving energy. The minimum system diagram is shown in Fig. 2.

\subsection{Street Lamp Fault Detection Circuit}

Because most of the community mainly adopts the time control method to realize the automatic control of the working states of street lamp, so when the street lights are not bright, the microcontroller should be able to automatically identify the reason out light is due to failure or due to the day. The detection circuit and control circuit of the system are shown in Fig. 2. Take a lamp as an example.

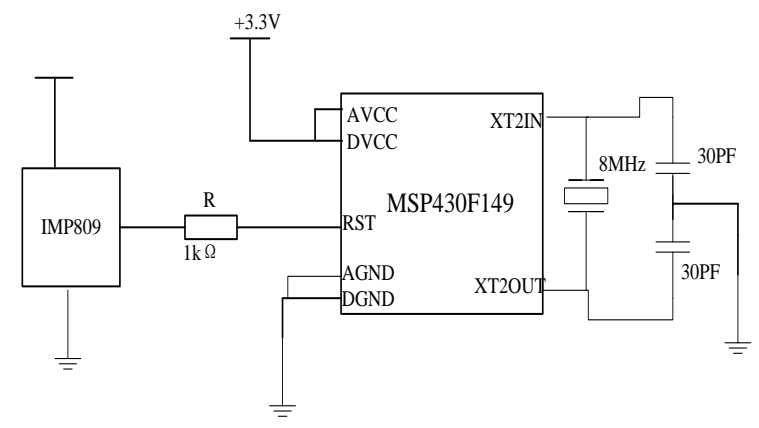

Fig. 2 Minimum system diagram of MSP430F149

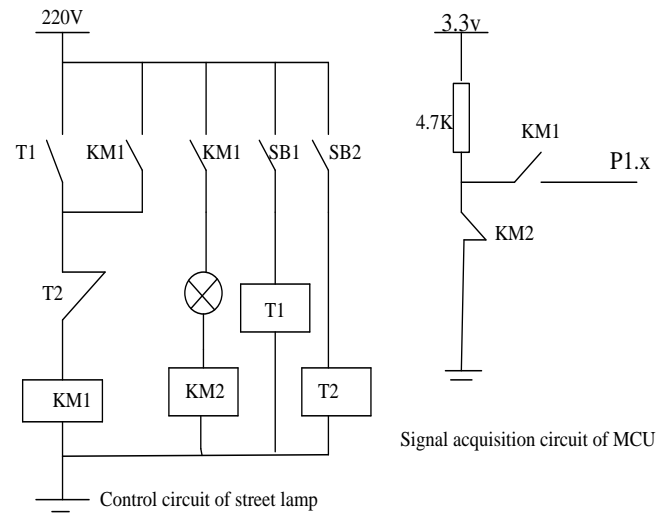

Fig. 3 Street lamp fault detection circuit 
The design uses two time relays T1 and T2, For example, the switch SB1 is closed at 19 o'clock, T1 coil is energized, after 24 hours, the normally open contact T1 is closed, the relay coil KM1 is electric, this means that the time is night, P1.x can read the information of street lights. Street lamps and relays KM2 coil are in series, when the street lamp is working normally, the KM2 gets electricity, its normally closed contact is disconnected, the P1.x gets a high level, which indicates that the street lamp is normal without fault; When the street lamp is failure, KM2 coil is loss of power, KM2 normally closed contact is closure, P1.x get a low level, indicating that the street lamp fault. The next day 7:00 closed SB2, the time relay T2 coil is electric, after 24 hours, T2 normally closed point off, KM1 loss of power, its normally open point off, P1.x hanging, single chip can't read the street light information, this indicates daylight.

\subsection{The Design of Wireless Communication Circuit}

This design uses the GSM wireless communication network which is not subject to time, space and distance to realize the remote centralized monitoring of all street lamps. Using TC35i industrial communication module of SIEMENS which supports Chinese SMS as a communication module of this design, the working voltage is 3.3V $\sim 4.8 \mathrm{~V}$, it can work in the EGSM900 and GSM1800 dual band, low power consumption and can transmit voice and data signals [4]. TC35i data interface can bidirectional transfer instructions and data, support Text and PDU format SMS (short message), can be achieved through the AT command or turn off the signal to restart and fault recovery. TC35i is composed of 6 parts, such as power supply module, flash memory, ZIF connector and antenna interface and so on. TC35i through the ZIF connector can be connected with the MCU. Because the TC35i is the CMOS level, and the MSP430 microcontroller output is the TTL level, therefore, this design uses the 74F07 to carry on the level conversion, in order to provide the enough big current. In the design we use MSP430F149's serial port URXD0 and UTXD0 (namely P3.6 and P3.7) and TC35i module 1 to communicate. The 5V power supply in the PC machine is used as the power supply of the GSM module 2, without the external power supply, which is convenient and simple.

The communication between the PC module and the GSM module only uses the serial port RXD, the TXD and the ground wire to complete $[2,5,6]$, the serial port RTS and the DTR and the module 2 control connection. The fault of street lamp, street lamp switch status and other information is sent to the host computer monitoring center by the TC35i module, which is displayed by the software of the monitoring center computer. The communication interface circuit is shown in Fig. 4.

\section{Design of Software}

The design of intelligent residential street lamp fault detection software is based on the C language, Detection software mainly includes the microcontroller $\mathrm{I} / \mathrm{O}$ port initialization procedures, communication module initialization procedures, the clock and inspection procedures. Its main program flow chart is shown in Fig. 5. The state of all street lights is checked timing by MCU, if there is a fault, the microcontroller will start the GSM module to send the details of the fault lamp to monitoring center, and sent it to the mobile phone, to achieve a dual reminder function. At the same time when the timer does not overflow, the microcontroller is into a low-power mode waiting for the next inspection, you can also set the time to monitor center to send each street lamp information freely.

We use VC ++ to develop the host computer monitoring software, the software man-machine interface is friendly, By configuring the operating mode of the TC35i, the real-time information exchange between it and the computer can be realized, We can use the host computer software to view the information of each street lamp in real time. The software can also be convenient to upgrade and improve. 


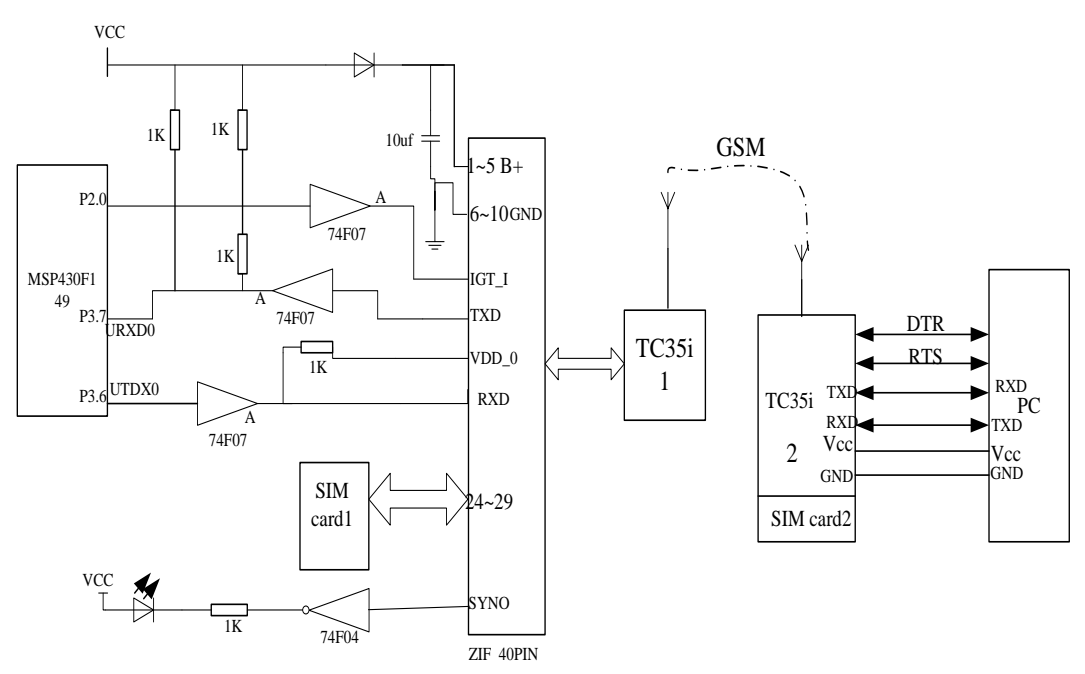

Fig. 4 Communication interface circuit

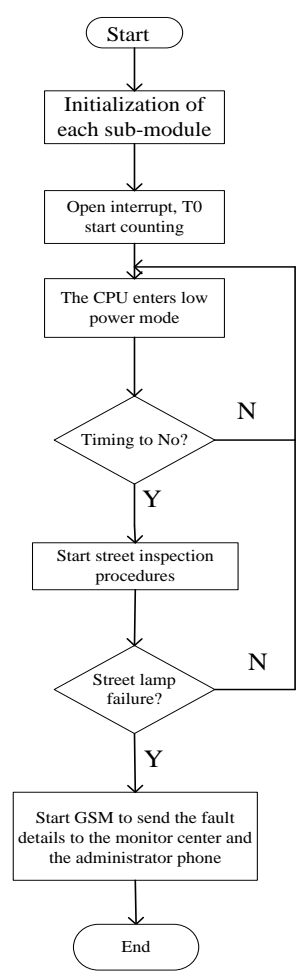

Fig. 5 Flow chart of the main program

\section{Conclusions}

The prototype of this design is carried out in a certain district. Experimental results show that: the control device can correctly judge the community street lights good or bad and the fault point location, Property management personnel only in the monitoring center can be easily through the GSM network to monitor the work state of all street lights. The information of the fault street lamp can be sent to the monitoring center of the host computer in a timely and alarm prompt. The application of the device in the modern management of the Intelligent Community street lamp will greatly reduce the cost of property management, while reducing the living costs of residents, reducing the residents' unnecessary damage due to street damage. This design can also be applied to the remote centralized monitoring and management of municipal street lamps.

\section{Acknowledgements}

This work was financially supported by Key Research Projects of Henan Province( 16B413007) in 2016 and Project of Zhengzhou Science and Technology Bureau(20150464) in 2016 funds.

\section{References}

[1] H. Zhou: Research on Energy Saving Control System of Intelligent Street Lamp (MS. Wuhan University of Technology, China 2009), p:34. (In Chinese)

[2] K. Xie and J. Zhao: MCU System's Design and Practice of MSP430 Series (Mechanical Industry Publications, China 2009), p.35-37. (In Chinese)

[3] R. Hua and P.Z. He: Modern Manufacturing Engineering, Vol. 12 (2013) No.3, p.86. (In Chinese)

[4] F. Zhao, Z.G. Qi and X.X. Zheng: Journal of Agricultural Mechanization Research, Vol. 37(2015) No.5, p. 88-90. (In Chinese)

[5] J.S. Zheng, J.J. Xu and S.Z. Li: Modern Manufacturing Engineering, Vol. 11(2012) No.4, p: 
85.

[6] Q. Wu and B. Wu: Chinese Science and Technology Online, Vol. 2(2008) No.3,p: 137-138. 